\title{
Selective laser melting of Al and AISi10Mg: parameter study and creep experiments
}

\author{
Torben Fiedler $^{1}\left(\mathbb{D} \cdot\right.$ Kai Dörries $^{1} \cdot$ Joachim Rösler ${ }^{1}$
}

Received: 17 June 2021 / Accepted: 4 December 2021 / Published online: 16 December 2021

(c) The Author(s) 2021

\begin{abstract}
Selective laser melted (SLM) aluminum alloys are widely used for many technical applications. However, the application is limited to low temperatures due to their relatively poor creep resistance. The creep resistance and strength could be enhanced by oxide dispersion-strengthening. A hypothesis is that oxygen intake during selective laser melting can lead to formation of fine aluminum oxides and thus strengthen the SLMed part. To elucidate this in more detail, selective laser melted AlSil0Mg was tested in creep experiments at temperatures of $300^{\circ} \mathrm{C}$. Although, in other studies at lower temperatures, a relatively large stress exponent for creep was found, the high temperatures in this work led to a creep exponent of just 7 to 8 , indicating no significant dispersion strengthening. Furthermore, for future research, it was necessary to investigate the feasibility of SLM with pure aluminum. For this purpose, a parameter study was carried out and an optimum parameter set for pure aluminum was found. Dense samples with a porosity below $0.2 \%$ were produced. Selective laser melting was carried out with a varying oxygen content in the inert-gas atmosphere to elucidate the hypothetic strengthening effects by oxygen intake. However, even at $800 \mathrm{ppm}$ oxygen in the atmosphere, no effect on hardness and microstructure could be observed.
\end{abstract}

Keywords Selective laser melting $\cdot$ Laser powder bed fusion $\cdot$ AlSi10Mg $\cdot$ Creep $\cdot$ Pure aluminium $\cdot$ Parameters

\section{Introduction}

Aluminum alloys additively manufactured by selective laser melting (SLM) have a great potential for many technical applications due to their low mass density and high electrical and thermal conductivity. However, aluminum has a relatively low strength. Although precipitation- or solid-solution strengthened aluminum alloys are commercially available and successfully used for several different applications, their performance at temperatures above $200{ }^{\circ} \mathrm{C}$ is poor due to microstructural changes.

One of the most commonly used aluminum alloys for selective laser melting is AlSi10Mg [1-3] with an aluminum-rich as well as a silicon-rich solid solution phase. The latter has an absorption coefficient for laser radiation ten times the coefficient of pure aluminum at a laser wavelength of $1 \mu \mathrm{m}$, which greatly enhances the meltability of this alloy in SLM [1].

Torben Fiedler

t.fiedler@tu-braunschweig.de

1 Institute for Materials Science, Technische Universität Braunschweig, Braunschweig, Germany
SLMed Al-alloys have a very fine grained microstructure (approx. $0.5 \mu \mathrm{m}$ grain size [2]), caused by the rapid cooling in the SLM process (in the order of magnitude of $10^{3} \mathrm{~K} / \mathrm{s}$ and above [1] to $10^{6} \mathrm{~K} / \mathrm{s}$ [4]). In case of the AlSi10Mg alloy, the rapid cooling in SLM leads to very fine Si precipitates and a supersaturation of the $\mathrm{Al}$ matrix with $\mathrm{Si}$. In contrast, cast AlSi10Mg consists of a dendritic microstructure with an eutectic Si-rich phase. The SLM microstructure leads to a hardening effect: Sercombe et al. [1] report an increase in room temperature strength of approximately $30 \%$ compared to cast material.

Even at intermediate temperatures below $200{ }^{\circ} \mathrm{C}$, creep plays an important role in aluminum alloys due to the low melting point of aluminum. In SLMed AlSi10Mg alloy, two contrary effects are of importance: On the one hand, the fine grained microstructure may reduce the creep resistance, while on the other hand, the fine precipitates may cause strengthening. Only a few studies investigated the creep behavior of SLMed AlSi10Mg so far [5-8]. They found that the creep resistance of SLMed AlSi10Mg is significantly better than of conventionally cast AlSi10Mg. A power-law stress exponent of 16 to 25 was found [5-7]. For conventionally cast AlSi $10 \mathrm{Mg}$, a stress exponent of only 9 to 13 
was reported [9]. It was assumed that the high values of stress exponent in the SLMed alloy are due to strengthening by small silicon precipitates in the aluminum matrix [7], but further investigation was not carried out. However, the small precipitates tend to coarsen after longer heat exposure [10], so that the increased creep resistance of the SLMed $\mathrm{AlSi} 10 \mathrm{Mg}$ alloys must be somehow limited to relatively low temperatures.

Creep resistant aluminum alloys could be strengthened by fine dispersoids like aluminum oxide [11]. It has been shown that, in selectively laser melted aluminum, fine dispersed aluminum oxide particles may form during the manufacturing process $[1,12-14]$ which may lead to a dispersion strengthening of the material. The aluminum oxides arise on the one hand from the oxide layer on the powder particles which is broken up and dispersed in the melt pool [14]. On the other hand, residual oxygen in the SLM-chamber atmosphere leads to a thin oxide layer on the melt-pool surface, which is dispersed by strong convection in the melt pool $[1,15]$. Depending on the convection characteristics and the number and size of the dispersed oxide particles, oxide layers may not fully break up while collisions between particles may lead to an agglomeration and, consequently, relatively large dispersoid clusters may result. Thus, the size and distribution of these particles depend on the oxide content in the material $[15,16]$ as well as the laser power: higher power leads to a better convective flow field in the melt pool and a better distribution of fine oxide particles [12, 17]. The maximum oxygen intake is limited: to prevent balling during SLM, the oxygen content in aluminum is limited to $2.8 \%$ [18]. At a too high oxygen content in the inert-gas atmosphere, the formability of Aluminum in SLM is poor. The value of the maximum reasonable oxygen content is somewhere below $1000 \mathrm{ppm}$, according to the experiments done by Hu et al. and Louvis et al. [13, 19].

Intensive studies of the strengthening of SLMed Aluminum and its alloys by these oxides are still lacking. To investigate the oxide dispersion-strengthening mechanism in detail, studies on pure aluminum have to be carried out to exclude other strengthening effects. However, selective laser melting of pure aluminum is still challenging. The main issue is the relatively low absorption coefficient for laser radiation ( 0.07 at wavelengths of about $1 \mu \mathrm{m})$. Furthermore, aluminum powder is reported to have an irregular shape. Together with its relatively low mass density, the aluminum powder particles tend to bridge inside the conveying system and hinder the powder flow [19]. Due to these difficulties, there are only a few studies available in the literature working with pure aluminum [14], which benefit from the latest development in SLM-technology including higher laser power (for example [20]).

It is one goal of the present work to investigate the creep behavior of AlSi10Mg in more detail at a temperature of
$300{ }^{\circ} \mathrm{C}$, above the temperature in other studies from the literature. The influence of microstructural changes on the creep performance is investigated, and the role of potential dispersed aluminum oxides is discussed.

Furthermore, to provide a basis for detailed studies of the strengthening of SLMed aluminum alloys by internal oxides, a parameter study on technically pure aluminum was performed at oxygen-contents in the chamber-atmosphere of up to $800 \mathrm{ppm}$. The influence of SLM parameters on the macro- and microstructure were investigated and a parameter set for future studies on pure aluminum was defined. Furthermore, the influence of oxygen content on the hardness of the samples was analyzed to elucidate a strengthening effect by oxides arising from the oxygen content in the SLMchamber atmosphere.

\section{Methods}

\subsection{Selective laser melting}

The specimens were fabricated using an SLM125HL from SLM Solutions Group AG. The machine is equipped with a $400 \mathrm{~W}$ IPG fiber laser, which has a wavelength of $1070 \mathrm{~nm}$ and a beam diameter of $66.5 \mu \mathrm{m}$ (measured at a $40 \mathrm{~W}$ laser power). Samples were printed on an AlSi10Mg substrate plate with dimensions of $123 \times 123 \times 25 \mathrm{~mm}^{3}$, which was preheated to $200{ }^{\circ} \mathrm{C}$ to reduce residual stresses. The process chamber was purged with $99.999 \%$ pure argon inert gas, so that a nearly oxygen-free atmosphere can be achieved. During the process, the circulating argon shielding gas ensures that spatter and fumes are removed from the samples so as not to affect the laser beam.

For selective laser melting with an increased oxygen content, the process chamber was purged until an oxygen content of $800 \mathrm{ppm}$ was reached. At a higher oxygen content, the SLM process cannot be started due to safety regulations. During the SLM process, the remaining atmospheric oxygen content decreases due to oxidation of the hot melt pools. The atmospheric oxygen content in the process chamber is continuously measured by two oxygen sensors.

All samples were fabricated with $30 \mu \mathrm{m}$ layer thickness, and between each layer, the scan direction was rotated by $67^{\circ}$. A limiting window of $120^{\circ}$ was used, which means that laser tracks with angles outside this window are skipped. This ensures that laser paths must have a certain angle to the Ar-flow to ensure the removal of fumes, etc. Thus, movement of the laser in the Ar-flow direction can be avoided. The laser tracks are arranged in a stripe pattern, with a stripe length of $10 \mathrm{~mm}$.

The AlSi10Mg samples were cylindrical with a height of $20 \mathrm{~mm}$ and a diameter of $10 \mathrm{~mm}$, as these were used for compressive creep tests in addition to microstructure 
Table 1 SLM parameters for AlSi10Mg

\begin{tabular}{llll}
\hline $\begin{array}{l}\text { Hatch distance } \\
{[\mathrm{mm}]}\end{array}$ & $\begin{array}{l}\text { Laser power } \\
{[\mathrm{W}]}\end{array}$ & $\begin{array}{l}\text { Scan speed } \\
{[\mathrm{mm} / \mathrm{s}]}\end{array}$ & $\begin{array}{l}\text { Energy density } \\
{\left[\mathrm{J} / \mathrm{mm}^{3}\right]}\end{array}$ \\
\hline 0.13 & 350 & 1650 & 54 \\
\hline
\end{tabular}

Table 2 SLM parameter for pure Aluminum

\begin{tabular}{|c|c|c|c|c|}
\hline Sample & $\begin{array}{l}\text { Hatch dis- } \\
\text { tance }[\mathrm{mm}]\end{array}$ & $\begin{array}{l}\text { Laser } \\
\text { power [W] }\end{array}$ & $\begin{array}{l}\text { Scan speed } \\
{[\mathrm{mm} / \mathrm{s}]}\end{array}$ & $\begin{array}{l}\text { Energy } \\
\text { density }[\mathrm{J} / \\
\left.\mathrm{mm}^{3}\right]\end{array}$ \\
\hline 1 & 0.10 & 350 & 800 & 146 \\
\hline 2 & 0.06 & 300 & 1800 & 93 \\
\hline 3 & 0.08 & 400 & 1800 & 93 \\
\hline 4 & 0.10 & 350 & 1200 & 97 \\
\hline 5 & 0.10 & 250 & 1200 & 69 \\
\hline 6 & 0.10 & 300 & 1400 & 71 \\
\hline 7 & 0.06 & 300 & 2000 & 83 \\
\hline 8 & 0.10 & 300 & 1800 & 56 \\
\hline 9 & 0.10 & 300 & 800 & 125 \\
\hline 10 & 0.10 & 400 & 1400 & 95 \\
\hline 11 & 0.08 & 350 & 2000 & 73 \\
\hline 12 & 0.10 & 350 & 1600 & 73 \\
\hline 13 & 0.06 & 350 & 2000 & 97 \\
\hline 14 & 0.10 & 350 & 2000 & 58 \\
\hline 15 & 0.10 & 400 & 1600 & 83 \\
\hline 16 & 0.10 & 400 & 1200 & 111 \\
\hline 17 & 0.08 & 350 & 1600 & 91 \\
\hline 18 & 0.10 & 400 & 1800 & 74 \\
\hline 19 & 0.10 & 400 & 600 & 222 \\
\hline 20 & 0.10 & 400 & 2200 & 61 \\
\hline 21 & 0.12 & 400 & 1200 & 93 \\
\hline 22 & 0.12 & 350 & 1000 & 97 \\
\hline 23 & 0.12 & 350 & 1400 & 69 \\
\hline 24 & 0.12 & 350 & 1600 & 61 \\
\hline 25 & 0.10 & 400 & 800 & 167 \\
\hline 26 & 0.12 & 400 & 2000 & 56 \\
\hline 27 & 0.12 & 400 & 1600 & 69 \\
\hline 28 & 0.10 & 300 & 1000 & 100 \\
\hline
\end{tabular}

investigations. The SLM parameters for AlSi10Mg samples are listed in Table 1.

The geometry of the technically pure aluminum samples was cube-shaped with an edge length of $10 \mathrm{~mm}$. The parameters for the pure $\mathrm{Al}$ samples are listed in Table 2.

The height of the support structure was $4 \mathrm{~mm}$ for the AlSi10Mg samples. For pure aluminum, the support structure was only $0.5 \mathrm{~mm}$ high to be able to use the slightly increased oxygen content at the start of the process. The samples were removed from the substrate plate mechanically by a band saw.

Nitrogen gas atomized AlSi10Mg powder with a particle size of 20 to $63 \mu \mathrm{m}$ was obtained from SLM Solutions. Technically pure aluminum powder was obtained from TLS Technik. It has a size of 20 to $63 \mu \mathrm{m}$ with a mean particle diameter of $44.6 \mu \mathrm{m}$. Figure 1 shows the shape of the pure Al powder-particles: They are spherical with a relatively smooth surface, which reduces the conveying-problems reported in other studies (see "Introduction"). The chemical composition and size of the powders is summarized in Table 3.

\subsection{Creep experiments}

Creep experiments were carried out in a $50 \mathrm{kPa}$ Argon atmosphere with an inductive heating of the samples. The samples were tested at a nominal temperature of $300{ }^{\circ} \mathrm{C}$, which means that the testing temperature in the middle of the specimen was $300.0{ }^{\circ} \mathrm{C} \pm 0.1^{\circ} \mathrm{C}$ during the whole test. Due to the heat flux into the water cooled push rods, the temperature at the top and at the bottom of the samples was between $289^{\circ} \mathrm{C}$ and $297{ }^{\circ} \mathrm{C}$. It took $350 \mathrm{~s}$ to heat the sample to $300{ }^{\circ} \mathrm{C}$.

The top- and bottom base of the cylindrical samples were turned to obtain parallel and planar surfaces, the side surface was kept in the as printed condition. The load was applied in printing direction, as the samples were printed in axial direction.

For each sample, the creep experiment was performed in different steps with different loading conditions. The first
Fig. 1 Al-powder used in this study, SEM images
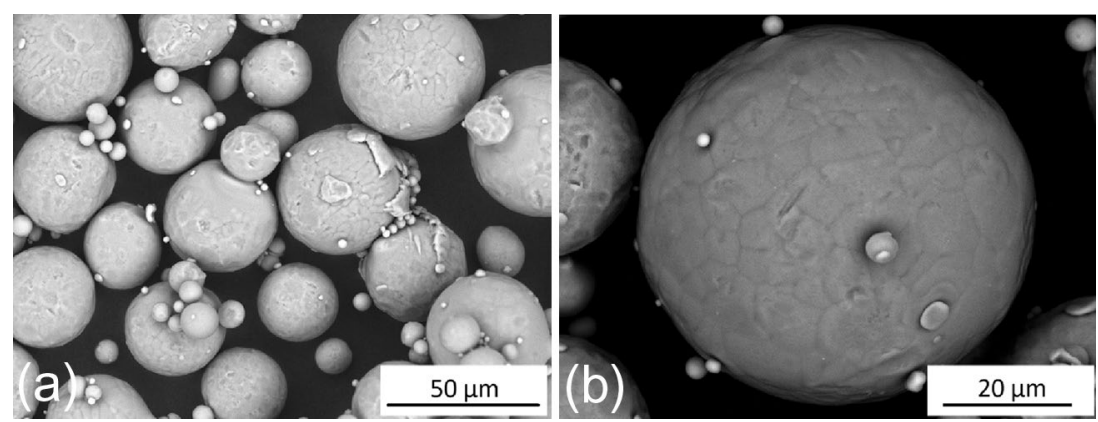
Table 3 Size $(\mu \mathrm{m})$ and chemical composition (weight-\%) of the powders used for SLM

\begin{tabular}{llllllll}
\hline & Size & $\mathrm{Al}$ & $\mathrm{Si}$ & $\mathrm{Mg}$ & $\mathrm{Fe}$ & $\mathrm{Ni}+\mathrm{Cu}$ & Other \\
\hline AlSi10Mg & $20-63$ & $\mathrm{Bal}$ & 9.8 & 0.35 & 0.14 & $<0.02$ & $<0.1$ \\
Al & $20-63$ & $>99.7$ & & & & & $(<0.3)$ \\
\hline
\end{tabular}

Table 4 List of creep samples and their loading conditions. Temperature for testing and aging was $300{ }^{\circ} \mathrm{C}$

\begin{tabular}{|c|c|c|c|c|c|}
\hline \multicolumn{6}{|c|}{ Strain-rate controlled experiments } \\
\hline \multirow[t]{2}{*}{ Specimen No } & \multirow[t]{2}{*}{ Pre-treatment } & \multicolumn{2}{|l|}{ Step 1} & \multicolumn{2}{|l|}{ Step 2} \\
\hline & & $\dot{\varepsilon}\left[\mathrm{s}^{-1}\right]$ & Time $[\mathrm{h}]$ & $\dot{\varepsilon}\left[\mathrm{s}^{-1}\right]$ & Time $[\mathrm{h}]$ \\
\hline 1 & - & $8.0 \cdot 10^{-7}$ & 9.2 & $1.6 \cdot 10^{-6}$ & 4.4 \\
\hline 2 & - & $1.0 \cdot 10^{-5}$ & 2.8 & & \\
\hline 3 & Aged $108 \mathrm{~h}$ & $8.3 \cdot 10^{-7}$ & 9.2 & $1.6 \cdot 10^{-6}$ & 4.4 \\
\hline 4 & - & $8.3 \cdot 10^{-7}$ & 9.2 & $1.6 \cdot 10^{-6}$ & 4.4 \\
\hline 5 & - & $8.3 \cdot 10^{-7}$ & 7.1 & $1.0 \cdot 10^{-6}$ & 0.7 \\
\hline
\end{tabular}

Stress-controlled experiments (technically, the experiments were force-controlled. The force was calculated from the given stress and the initial cross-sectional area)

\begin{tabular}{|c|c|c|c|c|c|c|c|c|c|}
\hline \multirow[t]{2}{*}{ Specimen No } & \multirow[t]{2}{*}{ Pre- treatment } & \multicolumn{2}{|l|}{ Step 1} & \multicolumn{2}{|l|}{ Step 2} & \multicolumn{2}{|l|}{ Step 3} & \multicolumn{2}{|l|}{ Step 4} \\
\hline & & $\sigma[\mathrm{MPa}]$ & Time $[\mathrm{h}]$ & $\sigma[\mathrm{MPa}]$ & Time $[\mathrm{h}]$ & $\sigma[\mathrm{MPa}]$ & Time $[\mathrm{h}]$ & $\sigma[\mathrm{MPa}]$ & Time $[\mathrm{h}]$ \\
\hline 6 & Aged $108 \mathrm{~h}$ & 19 & 25.6 & & & & & & \\
\hline 7 & Aged $108 \mathrm{~h}$ & 18 & 7.8 & 20 & 10.6 & 22 & 4.4 & 25 & 5.6 \\
\hline
\end{tabular}

samples were tested with a constant strain rate to account for the unknown creep properties and the unknown test durations when tested with constant loads. Due to the better known creep properties, the last two samples could be tested with a constant load. Some samples were aged at $300^{\circ} \mathrm{C}$ for $108 \mathrm{~h}$ prior to the creep test by heating the sample in the creep-testing machine without applying any loads. Table 4 shows all samples and the loading conditions.

\subsection{Metallographic examination}

For microstructural observation, the samples were polished and etched in a solution of $30 \mathrm{ml}$ water, $10 \mathrm{ml}$ hydrofluoric acid and $60 \mathrm{ml}$ hydrogen peroxide. For a better visibility of the melt track in pure aluminum, these samples were etched for $3 \mathrm{~min}$ in 5\% aqueous $\mathrm{NaOH}$-solution. Optical microscopy, scanning electron microscopy (SEM) and electron dispersive X-ray (EDX) measurements were used to investigate the microstructure.

The dimensions of the melt tracks were measured in the vertical cross section perpendicular to the scan tracks at $100 \times$ magnification in the optical microscope. Only the melt tracks on the upper surface were measured, where their orientation could be easily determined. Figure 2 shows how the width and height were measured.

To measure the porosity of the pure Al samples, four optical micrographs evenly distributed over the polished

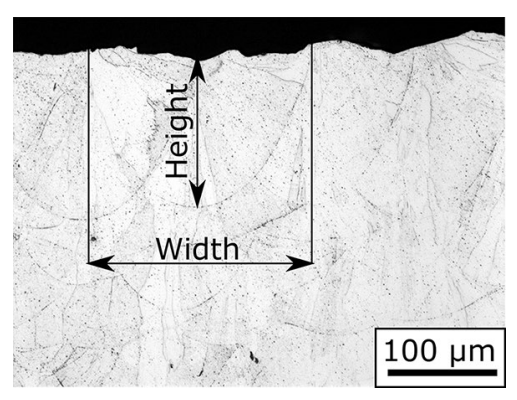

Fig. 2 Definition of width and height of the melt tracks in the microstructure of selective laser melted pure aluminum, etched with $\mathrm{NaOH}$ solution

vertical cross section were captured for each sample. The micrographs were taken in about $1 \mathrm{~mm}$ distance to the specimen surfaces at each corner of the sample. Each micrograph covered an area of $1.8 \mathrm{~mm} \times 1.3 \mathrm{~mm}$. The porosity was determined by measuring the pore fraction in the images using the software ImageJ. Due to the relatively rough surface of some samples, a density measurement by the Archimedes method might be inaccurate due to small adhering gas bubbles.

Hardness was measured with a Vickers indenter at a force of $0.3 \mathrm{kp}$. 


\section{Results and discussion}

\subsection{Microstructure of SLMed AISi10Mg}

Figure 3 shows the microstructure of the AlSi10Mg samples after SLM. It consists of primary aluminum-rich grains and, in between, a network consisting of eutectic islands and connected Si particles. In the $\mathrm{Al}$ grains, particles with a size in the order of magnitude of $10 \mathrm{~nm}$ have formed as well as larger particles. The latter could be identified with EDX as secondary Si-rich precipitates, probably formed by additional heat intake during the melting of adjacent melt tracks in the SLM-process. The small particles will be discussed later on, see below.

During the creep experiments, the intergranular network is broken up, and the Si particles have coarsened at $300{ }^{\circ} \mathrm{C}$ (see Fig. 4b). The fine particles in the order of magnitude of $10 \mathrm{~nm}$, as already seen in the as printed condition (see previous paragraph), were still observed in the Al-matrix. These particles could not be identified within the present study. Probable phases in AlSi10Mg alloys,

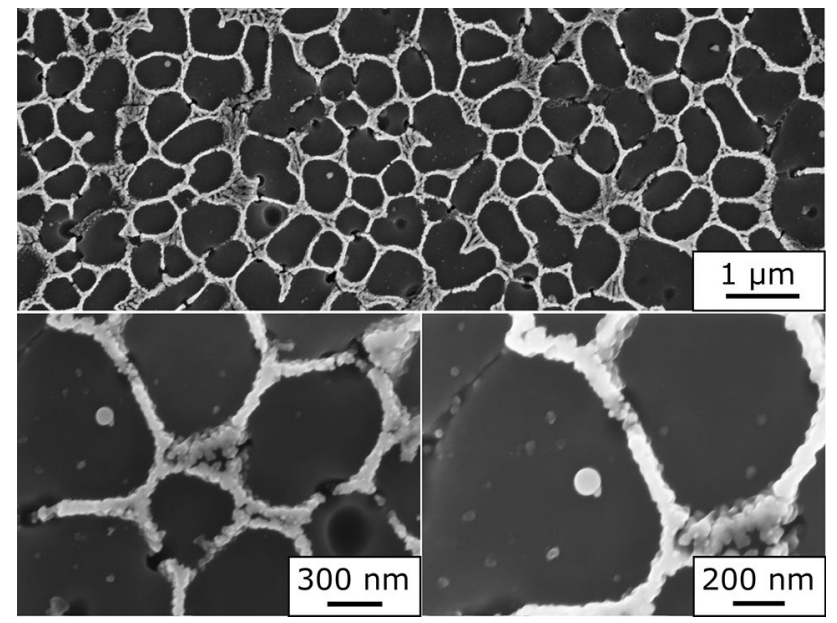

Fig. 3 Microstructure of selective laser melted AlSi10Mg (SEM images): primary solidified $\mathrm{Al}$ rich phase (dark) and eutectic Si particles (bright) as reported in the literature, are $\mathrm{Mg}_{2} \mathrm{Si}$ particles, secondary $\mathrm{Si}$ precipitates, or intermetallic $\mathrm{Fe}$-rich phases. The $\mathrm{Fe}$-rich intermetallics are either plate-shaped or become unstable at high temperatures [9]. Si precipitates would have coarsened during high temperatures. According to $[4,10]$, the $\mathrm{Mg}_{2} \mathrm{Si}$ particles form mostly in between the Si-rich particles, since the heat intake by adjacent layers during SLM is large enough for the Mg to diffuse towards the intergranular areas. EDX measurements revealed no $\mathrm{Mg}$ rich phase in the as received condition, probably because the $\mathrm{Mg}_{2} \mathrm{Si}$ particles were much smaller than the accuracy of the EDX method. After heat exposure during the creep experiments, large spots with a high $\mathrm{Mg}$ and $\mathrm{Si}$ concentration could be observed with EDX (see Fig. 5), which indicates that the $\mathrm{Mg}_{2} \mathrm{Si}$ phase is coarsened at high temperatures. This coarsening effect was also observed by Izcara in cast AlSi10Mg [9]. Thus, it is very likely, that the small particles remaining in the Al matrix are oxides.
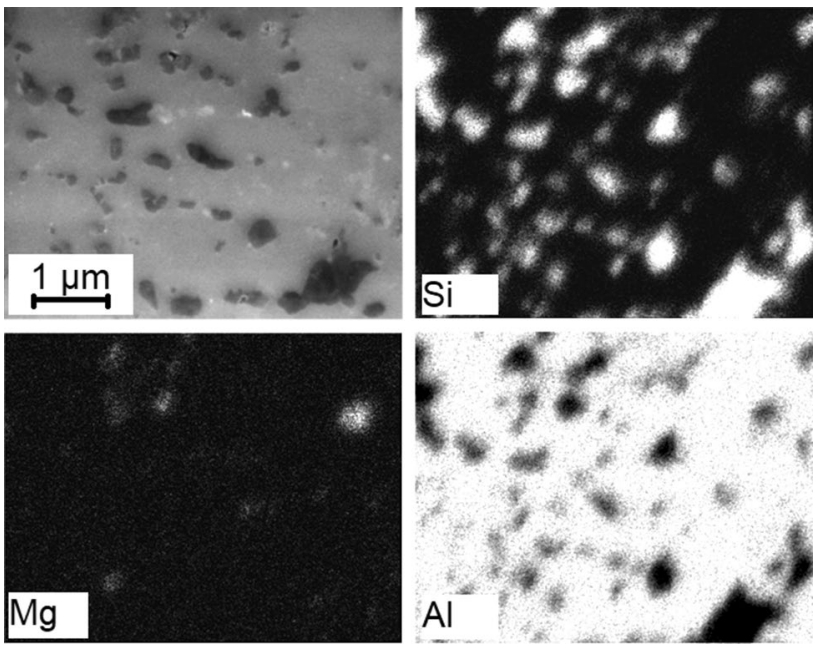

Fig. 5 EDX-analysis ( $5 \mathrm{kV}$ voltage) of the AlSi10Mg microstructure after creep experiments at $300{ }^{\circ} \mathrm{C}$ : Secondary electron image (top left) and X-ray signals of $\mathrm{Si}, \mathrm{Mg}$, and $\mathrm{Al}$. The microstructure was not etched
Fig. 4 Comparison of the etched AlSi10Mg microstructure: (a) The as received condition for comparison and (b) after creep experiments at $300{ }^{\circ} \mathrm{C}$ (specimen 3 according to Table 4): the network between the aluminumrich grains is broken up, and $\mathrm{Si}$ particles have coarsened
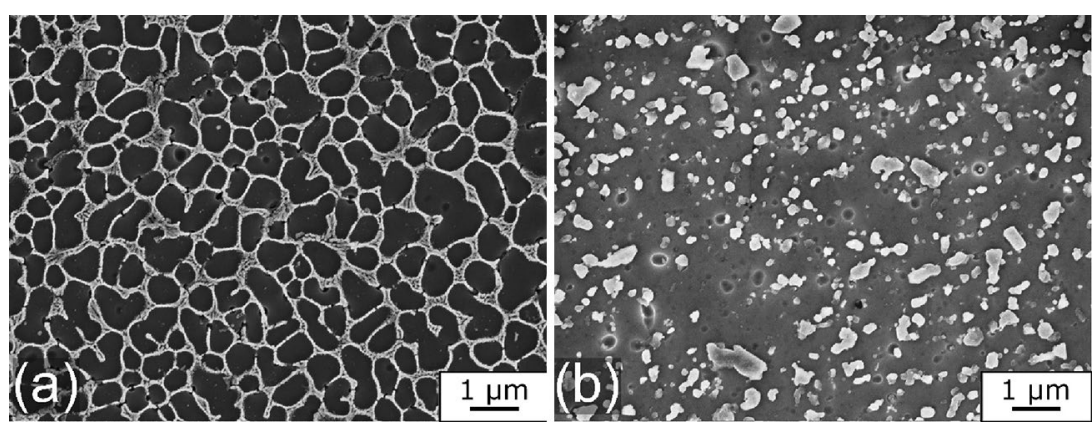


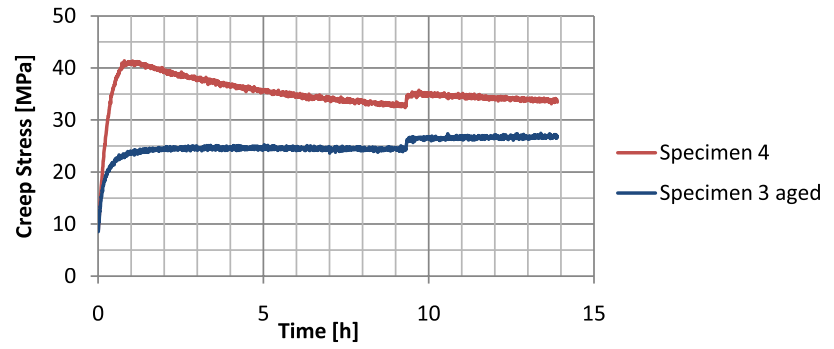

Fig. 6 Creep stress in SLMed AlSi10Mg at a constant strain rate of $8.3 \times 10^{-7} \mathrm{~s}^{-1}(<9.2 \mathrm{~h})$ and $1.6 \times 10^{-6} \mathrm{~s}^{-1}(>9.2 \mathrm{~h})$ at $300{ }^{\circ} \mathrm{C}$

\subsection{Creep experiments with AISi10Mg}

Figure 6 shows creep curves of a two-step experiment with a strain rate of $8.3 \cdot 10^{-7} \mathrm{~s}^{-1}$ in the first and $1.6 \cdot 10^{-6} \mathrm{~s}^{-1}$ in the second step. In the as received condition (specimen 4 ), creep commences at a stress of about $8 \mathrm{MPa}$. During primary creep, the stress increases quickly to a maximum of about $40 \mathrm{MPa}$ and diminishes then. A clear steady state is never reached. The aged specimen starts at a similar stress level, followed by an increasing stress during primary creep. However, strengthening during primary creep is less pronounced and a steady state, i.e. secondary creep, is quickly obtained. A qualitatively similar behavior can be observed in the second step of the experiment, when the strain rate is increased to $1.6 \cdot 10^{-6} \mathrm{~s}^{-1}$ after $9.2 \mathrm{~h}$. The stress in the as received sample reaches a maximum of $35 \mathrm{MPa}$ in the beginning of step 2 and decreases again and approaches slightly the curve of the as received sample.

These observations can be explained as follows: creep sets in by the deformation of the soft aluminum matrix, leading to comparable initial stress levels in both conditions. In case of the as received material, further creep deformation is quickly hindered by the intergranular network, causing substantial strengthening. However, as Fig. 3 shows, this network is not stable at $300{ }^{\circ} \mathrm{C}$. As it starts to break up and coarsens, the creep resistance diminishes, thus, causing a strength maximum. The microstructural evolution of the initial network never finishes during the duration of the creep test. Consequently, a steady state is never reached. Loss in creep strength due to these microstructural changes is substantial: the creep stress is reduced by $>20 \%$ at the end of step 1 compared to the maximum stress. Although the strain rate in step 2 was higher, the initial stress maximum from step 1 could not be reached due to the microstructural changes.

In case of specimen 3 , aging at $300{ }^{\circ} \mathrm{C}$ prior to creep testing was significantly longer $(108 \mathrm{~h})$ than the creep test itself. This led to a stable microstructure during creep testing, so that a steady state was quickly obtained. As the intergranular network was already broken up after aging, initial strengthening was less pronounced compared to the as received material.

The reinforcing effect by the intergranular network has also been investigated by Uzan et al. [6]: They found a low dislocation density in the Al phase after creep experiments, indicating rapid recovery processes at high temperatures, whereas in the Si phase, a dramatic increase of dislocation density was observed. If the Si-particles coarsen during ageing and the Si-rich network breaks up, the reinforcement effect is massively reduced.

Figure 7 shows the strain rate and corresponding stress for all creep experiments in a double-logarithmic representation (the stress maximum and, for the aged samples, the steady-state values). With increasing aging time, the values approach the values of the fully aged AlSi10Mg samples. The latter follow the power-law with a stress exponent of $n=7.2$. Slopes can be also assigned to the data of the as received material, leading to a value of 7.6, almost similar to the values of the aged samples. However, as steady state is not reached, these values should not be considered as stress exponents for steady-state power law creep.

The stress exponent observed by Uzan et al. [5, 6] was 16 (compression) and 25 (tensile), Paoletti et al. [7] reported a stress exponent of 18-24 (tensile) for SLMed AlSi $10 \mathrm{Mg}$ alloys at temperatures up to $225^{\circ} \mathrm{C}$. Paoletti et al. postulated that these high values are caused by the reinforcement by fine silicon particles. With this interpretation in mind, the much lower stress exponent observed here at $300{ }^{\circ} \mathrm{C}$ may be attributed to the observed coarsening of the silicon precipitates at that temperature. If the dispersed oxide particles played a significant role, the stress exponent in the experiments at $300{ }^{\circ} \mathrm{C}$ would be higher than observed here. For example, Rösler et al.

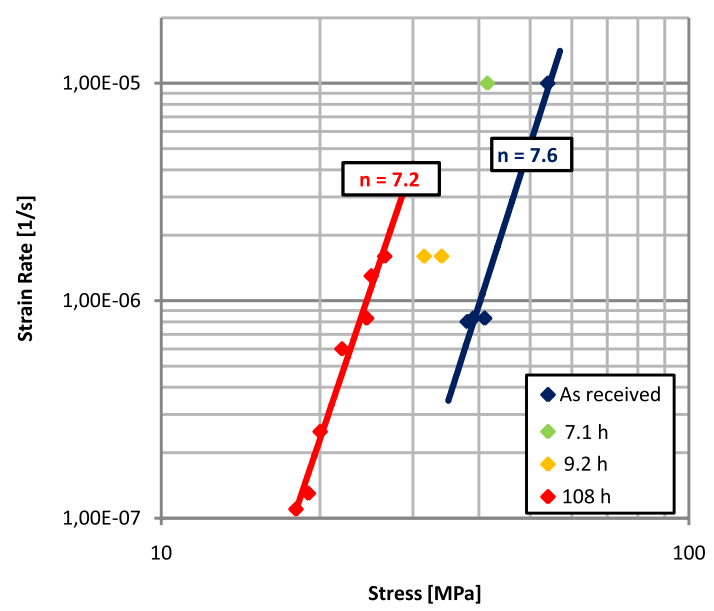

Fig. 7 Strain rate and stress at $300{ }^{\circ} \mathrm{C}$ for AlSi10Mg samples with different thermal history (aging prior to the creep test and during previous test steps) at $300{ }^{\circ} \mathrm{C}$. The variable $\mathrm{n}$ indicates the calculated power-law stress exponent 
investigated powder metallurgically processed aluminum alloys, dispersion strengthened by $\mathrm{Al}_{2} \mathrm{O}_{3}, \mathrm{MgO}$ and $\mathrm{Al}_{4} \mathrm{C}_{3}$ particles [11]. In all cases, they found stress exponents in excess of 50 for the temperature and strain rates considered here. Note also, that $\mathrm{MgO}$ rather than $\mathrm{Al}_{2} \mathrm{O}_{3}$ may form in $\mathrm{Mg}$-containing aluminum alloys [11].

\subsection{Parameter study on pure aluminum}

All samples were printed successfully. Large geometrical deviations were observed only at energy densities above $150 \mathrm{~J} / \mathrm{mm}^{3}$, where the cube shaped samples had a concave top surface after printing, probably caused by large residual stresses and shrinking. Every sample had a number printed on the top. But mostly, these numbers were not printed accurately (see Fig. 8a, c, e). Although these numbers were printed sufficiently with other materials, pure aluminum seems to require a larger wall thickness of these thin structures. This effect should be elucidated in the future if smaller parts with more complex geometries are produced.

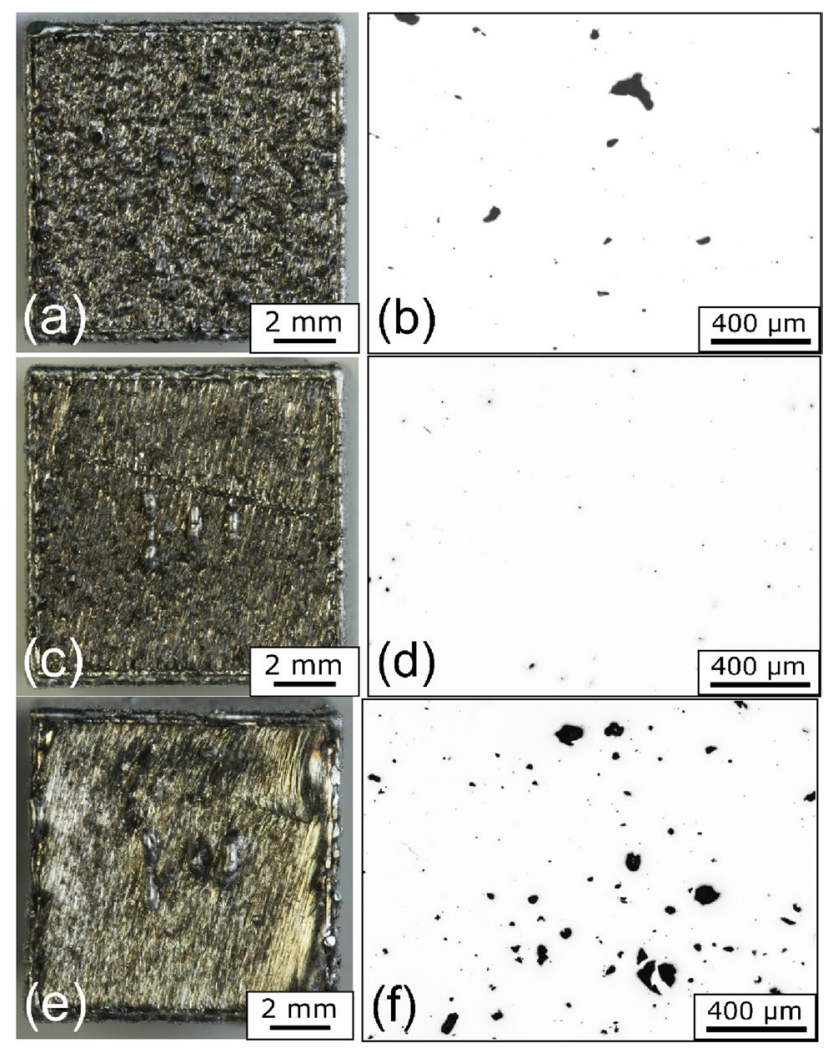

Fig. 8 Surface (a, c, e) and cross section (b, d, f) (build direction from bottom to top) of pure aluminum samples produced with an energy density of $(\mathbf{a}, \mathbf{b}): 61 \mathrm{~J} / \mathrm{mm}^{3},(\mathbf{c}, \mathbf{d}): 95 \mathrm{~J} / \mathrm{mm}^{3}$, and $(\mathbf{e}, \mathbf{f}): 222 \mathrm{~J} /$ $\mathrm{mm}^{3}$ at $400 \mathrm{~W}$ laser power, hatch distance $0.1 \mathrm{~mm}$ (Samples 20, 10, 19)

\subsubsection{Porosity}

Figure 9 shows the measured porosity versus the energy density for the different hatch distances $0.06 \mathrm{~mm}$ to $0.12 \mathrm{~mm}$. The porosity reached a minimum at energy densities between $75 \mathrm{~J} / \mathrm{mm}^{3}$ and $95 \mathrm{~J} / \mathrm{mm}^{3}$ for hatch distances of $0.08 \mathrm{~mm}$ and $0.10 \mathrm{~mm}$ (see Fig. $8 \mathrm{~d}$ for $95 \mathrm{~J} / \mathrm{mm}^{3}$ ). At higher energy densities above ca. $150 \mathrm{~J} / \mathrm{mm}^{3}$, large, mostly spherical gas pores were observed (see Fig. $8 \mathrm{f}$ for $222 \mathrm{~J} / \mathrm{mm}^{3}$ ). These pores may be caused by sputters of the melt pool and trapping of gas from the inert-gas atmosphere [14] caused by large convective flow in the melt pool due to Marangoni and recoil forces [21]. At too low energy densities, un-molten particles may lead to the formation of irregularly shaped pores. Furthermore, the surface of samples with low energy density is rough and uneven. The adjacent powder-layer thickness may exceed the height of the melt pool in the valleys of the surface roughness.

Based on the results shown in Fig. 9, the lowest porosity could be achieved with hatch distances of $0.08 \mathrm{~mm}$ and $0.1 \mathrm{~mm}$. However, only a few samples were produced at hatch distances different from $0.1 \mathrm{~mm}$, and further investigation could be carried out to narrow down the perfect value for the hatch distance.

Figure 10 shows the porosity versus energy density for different laser power values. It shows that the relation of porosity and energy density is nearly independent from the laser power in the investigated parameter range. However, since the lowest porosity has been achieved with $400 \mathrm{~W}$, and higher power leads to less production time, a power of $400 \mathrm{~W}$ can be recommended for further studies.

\subsubsection{Hardness}

A significant influence of the parameters on the hardness was not observed. Figure 11 shows, for example, the mean values and standard deviations from the hardness measurements on

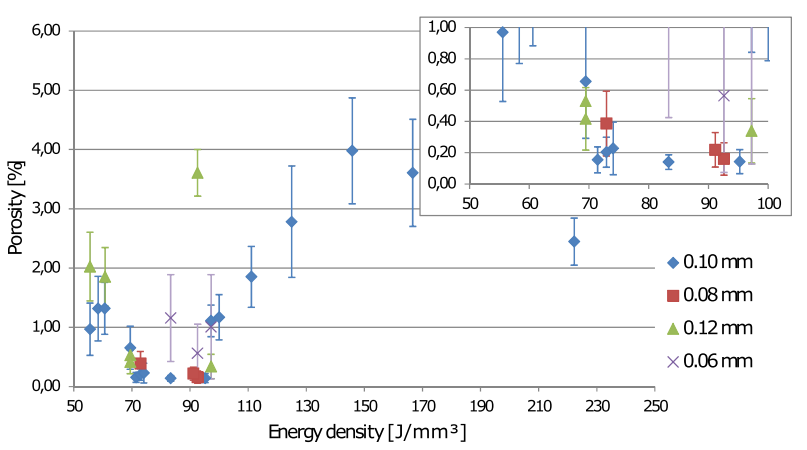

Fig. 9 Porosity of the Al SLM samples depending on the energy density for different hatch distances. Inset: Detailed view of the bottom left corner of the diagram 


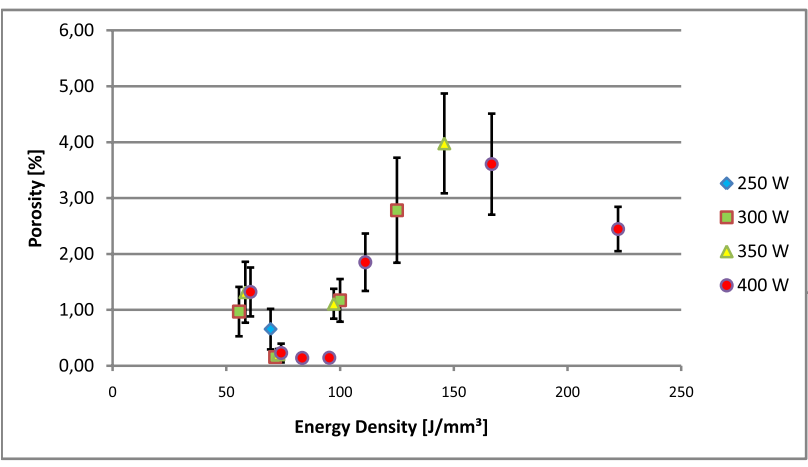

Fig. 10 Porosity versus energy density of pure aluminum manufactured with different laser power values and a hatch distance of $0.1 \mathrm{~mm}$

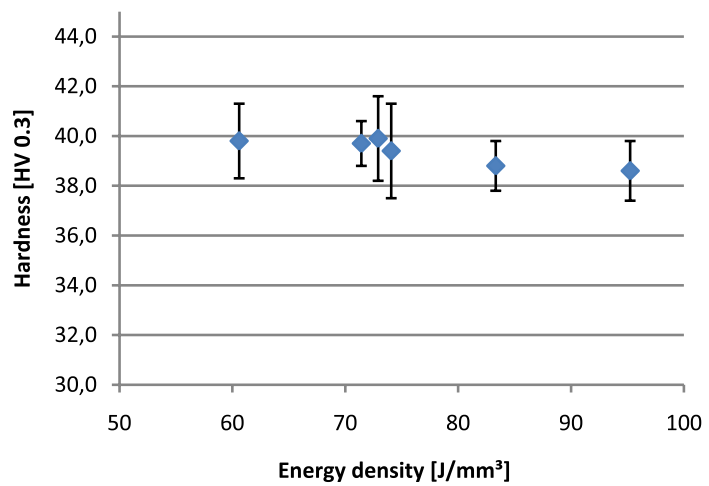

Fig. 11 Hardness versus energy density for pure aluminum samples with $0.1 \mathrm{~mm}$ hatch distance

samples with $0.1 \mathrm{~mm}$ hatch distance. With increasing energy density, the hardness decreases slightly, probably caused by the larger energy input. The larger energy input may lead to a slower cooling, which causes larger grains in the solidifying melt track. Furthermore, melt tracks from previous layers are heated again. In a certain heat-affected zone around the melt pool, this leads to recovery processes in the material. With increasing energy input, this heat-affected zone is larger, which decreases the macroscopic hardness of the material. It has to be noted that, due to the larger porosity, the hardness at $61 \mathrm{~J} / \mathrm{mm}^{3}$ may be underestimated by hidden pores. At energy densities above $100 \mathrm{~J} / \mathrm{mm}^{3}$, the high porosity made a reliable hardness measurement impossible.

It was supposed in the introduction that an increased oxygen content in the process chamber could possibly lead to a hardening effect due to small aluminum oxide particles in the aluminum matrix. To check this assumption, hardness profiles were measured on the vertical cross section of the samples on a track parallel to the buildup direction. According to these measurements, no influence of the oxygen content on the hardness was observed. Figure 12 shows, for example, the hardness of samples printed in the optimum
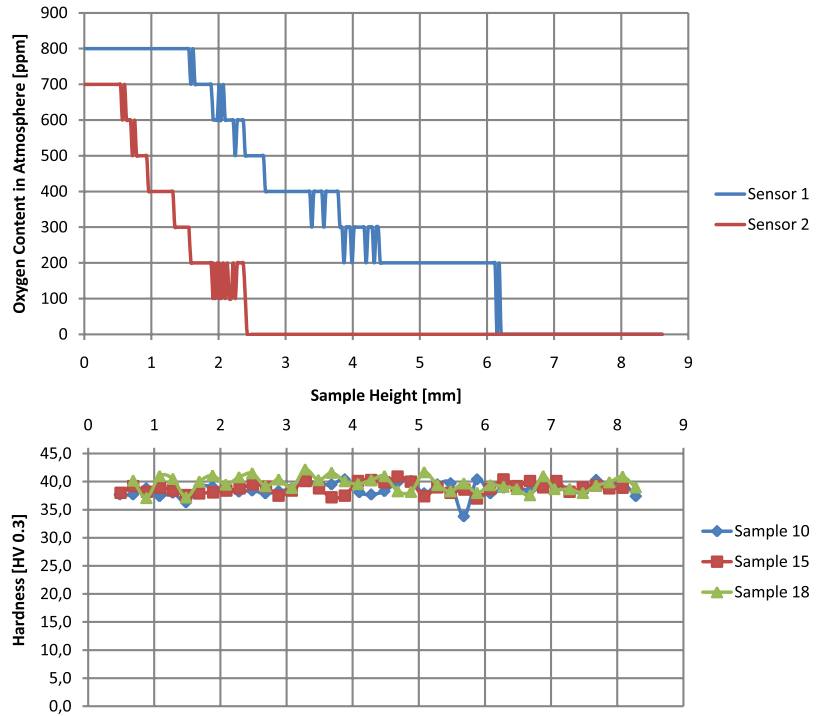

Fig. 12 Oxygen content during the buildup process and hardness of pure aluminum samples 10,15 and $18(0.1 \mathrm{~mm}$ hatch distance, energy density $74 \mathrm{~J} / \mathrm{mm}^{3}$ to $95 \mathrm{~J} / \mathrm{mm}^{3}$ ). Oxygen sensor one is located in the ceiling of the build chamber and sensor two is located in the shielding gas vent between the gas circulation pump and the chamber outlet

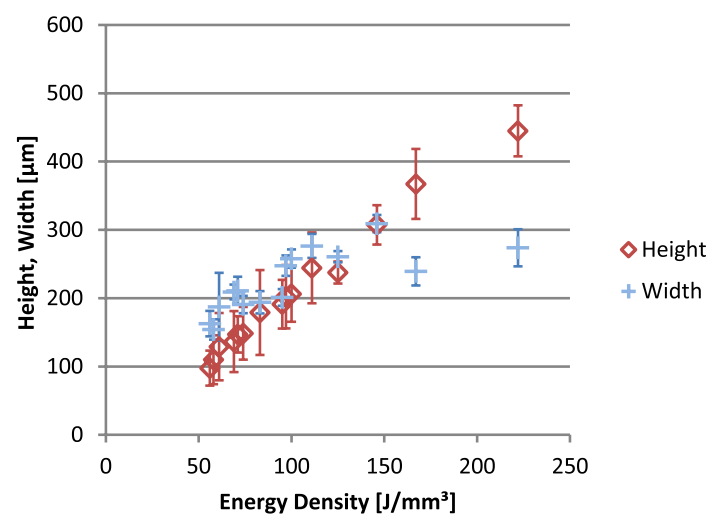

Fig. 13 Height and width of the scan tracks in pure aluminum at the upper surface

parameter range: although the oxygen content during the manufacturing of the first $1 \mathrm{~mm}$ sample height was $700 \mathrm{ppm}$ to $800 \mathrm{ppm}$ and decreased to $0 \mathrm{ppm}$ with increasing sample height, the hardness profile over the whole sample is nearly constant. Small variations of the hardness are independent from the oxygen content.

\subsubsection{Melt pool dimensions}

The height and width of the melt pools at the upper surface of the samples were measured and plotted in Fig. 13 for samples with $0.1 \mathrm{~mm}$ hatch distance. The height increases nearly linearly with the energy density. The width increases 


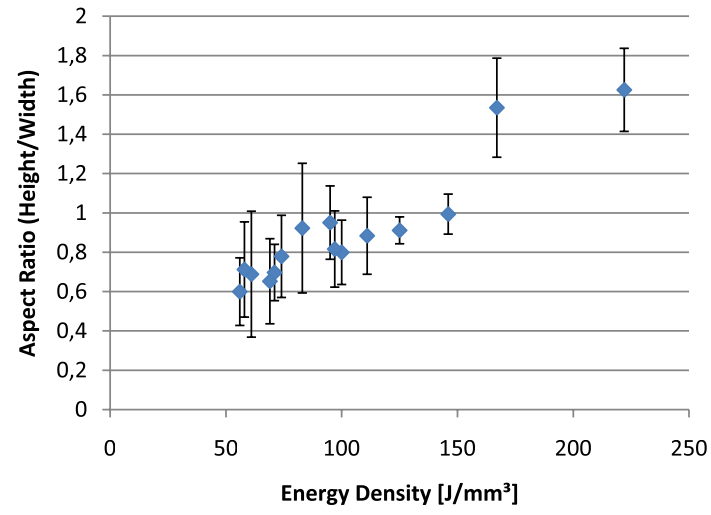

Fig. 14 Aspect ratio of the scan tracks according to Fig. 13

up to an energy density of approx. $150 \mathrm{~J} / \mathrm{mm}^{3}$, and drops to lower values at higher energy densities. This results in a large increase of the aspect ratio of the scan tracks above $150 \mathrm{~J} / \mathrm{mm}^{3}$, see Fig. 14: The melt pools become higher and narrower above a critical energy density somewhere between $150 \mathrm{~J} / \mathrm{mm}^{3}$ and $170 \mathrm{~J} / \mathrm{mm}^{3}$, where also large pores form in the base of the melt pool. This indicates keyhole mode for the melt pool above approximately $150 \mathrm{~J} / \mathrm{mm}^{3}$.

\section{Conclusions}

Creep experiments were carried out on SLMed AlSi10Mg alloys at $300{ }^{\circ} \mathrm{C}$. The stress exponent for creep was found to be 7 to 8 , and is much lower than one would expect for dispersion strengthened alloys. It was concluded that the high stress exponents reported elsewhere for lower temperatures may be mainly based on small precipitates by other alloying elements, which coarsen at the relatively high testing temperatures of $300{ }^{\circ} \mathrm{C}$ in this study. Thus, a strengthening effect by dispersed aluminum-oxides in the samples can be neglected here.

Furthermore, an SLM parameter-study on pure aluminum was carried out. It was found that an energy density of $75 \mathrm{~J} /$ $\mathrm{mm}^{3}$ to $95 \mathrm{~J} / \mathrm{mm}^{3}$ results in a porosity below $0.2 \%$. At lower energy densities, the bonding between the powder particles is too weak and the melt pools might be too small. Higher values result in large pores by spatter and trapping of gas from the SLM-chamber atmosphere. A transition to keyhole-mode was observed at approximately $150 \mathrm{~J} / \mathrm{mm}^{3}$. A hatch distance of $0.08 \mathrm{~mm}$ to $0.1 \mathrm{~mm}$ is optimal for pure aluminum. The layer thickness was $30 \mu \mathrm{m}$ and has not been varied in this study.

Summing up, optimum SLM parameters with the machine used here (SLM 125HL, SLM-solutions, Germany, $400 \mathrm{~W}$ fiber laser at $1070 \mathrm{~nm})$ for pure aluminum powder $(20 \mu \mathrm{m}$ to $63 \mu \mathrm{m})$ are:
- Hatch distance $0.1 \mathrm{~mm}$

- Layer thickness $0.03 \mathrm{~mm}$

- Scan speed $1600 \mathrm{~mm} / \mathrm{s}$

- Laser power $400 \mathrm{~W}$

- (resulting energy density: $83 \mathrm{~J} / \mathrm{mm}^{3}$ )

Acknowledgements The authors would like to thank Fabian Haase from the Institute for Materials Science, Technische Universität Braunschweig, for assisting with metallographic etching of the samples.

Author contributions Conceptualization: JR and TF; methodology and investigation: TF and $\mathrm{KD}$; formal analysis and investigation: TF; writing — original draft preparation: TF; writing—review and editing: JR and $\mathrm{KD}$; supervision: JR.

Funding Open Access funding enabled and organized by Projekt DEAL. No funding was received for conducting this study.

Availability of data and materials Raw data is archived at TU Braunschweig and is available upon request by the corresponding author or by the Institute for Materials Science (ifw @ tu-braunschweig.de).

\section{Declarations}

Conflict of interest The authors have no conflicts of interest to declare that are relevant to the content of this article.

Open Access This article is licensed under a Creative Commons Attribution 4.0 International License, which permits use, sharing, adaptation, distribution and reproduction in any medium or format, as long as you give appropriate credit to the original author(s) and the source, provide a link to the Creative Commons licence, and indicate if changes were made. The images or other third party material in this article are included in the article's Creative Commons licence, unless indicated otherwise in a credit line to the material. If material is not included in the article's Creative Commons licence and your intended use is not permitted by statutory regulation or exceeds the permitted use, you will need to obtain permission directly from the copyright holder. To view a copy of this licence, visit http://creativecommons.org/licenses/by/4.0/.

\section{References}

1. Sercombe TB, Li X (2016) Selective laser melting of aluminium and aluminium metal matrix composites: review. Mater Technol Adv Perform Mater 31(2):77-85. https://doi.org/10.1179/17535 55715Y.0000000078

2. Zhang D, Sun S, Qiu D, Gibson MA, Dargusch MS, Brandt M, Qian M, Easton M (2018) Metal alloys for fusion-based additive manufacturing. Adv Eng Mater. https://doi.org/10.1002/adem. 201700952

3. Yap CY, Chua CK, Dong ZL, Liu ZH, Zhang DQ, Loh LE, Sing SL (2015) Review of selective laser melting: materials and applications. Appl Phys Rev. https://doi.org/10.1063/1.4935926

4. Liu C, Zhao C, Zhou X, Shen Z, Liu W (2019) Microstructure of selective laser melted AlSi10Mg alloy. Mater Des. https://doi.org/ 10.1016/j.matdes.2019.107677

5. Uzan NE, Shneck R, Yeheskel O, Frage N (2018) High-temperature mechanical properties of AlSi10Mg specimens fabricated by 
additive manufacturing using selective laser melting technologies (AM-SLM). Addit Manuf 24:257-263. https://doi.org/10.1016/j. addma.2018.09.033

6. Uzan NE, Ratzker B, Landau P, Kalabukhov S, Frage N (2019) Compressive creep of AlSi10Mg parts produced by selective laser melting additive manufacturing technology. Addit Manuf. https:// doi.org/10.1016/j.addma.2019.100788

7. Paoletti C, Spigarelli S, Cabibbo M, Cerri E (2020) Creep behavior of a AlSiMg alloy produced by additive manufacturing. Proceedings of the TMS2020 $149^{\text {th }}$ Annual Meeting \& Exhibition 185-193. https://doi.org/10.1007/978-3-030-36296-6

8. Read N, Wang W, Essa K, Attallah MM (2015) Selective laser melting of AlSi10Mg alloy: process optimization and mechanical properties development. Mater Des 65:417-424. https://doi.org/ 10.1016/j.matdes.2014.09.044

9. Izcara XL (2016) Characterization and Modeling of the Influence of the Ageing Treatment on the Precipitation Process and the Mechanical Behavior of the $\mathrm{AlSi} 10 \mathrm{Mg}(\mathrm{Cu})$ Aluminum Alloy. Dissertation, TU Hamburg-Harburg, Germany. https://doi.org/10. $15480 / 882.1323$

10. Fousova M, Dvorský D, Michalcová A, Vojtěch D (2018) Changes in the microstructure and mechanical properties of additively manufactured AlSi10Mg alloy after exposure to elevated temperatures. Mater Charcter 137:119-126. https://doi.org/10.1016/j. matchar.2018.01.028

11. Rösler J, Joos R, Arzt E (1992) Microstructure and creep properties of dispersion-strengthened aluminum alloys. Metall Trans 23:1521-1539. https://doi.org/10.1007/BF02647335

12. Bajaj P, Hariharan A, Kini A, Kürsteiner P, Raabe D, Jägle EA (2020) Steels in additive manufacturing: a review of their microstructure and properties. Mater Sci Eng A. https://doi.org/10. 1016/j.msea.2019.138633

13. Hu Z, Zhu H, Nie X, Zhang C, Zhang H, Zeng X (2018) On the role of atmospheric oxygen into mechanical properties and fracture behavior of selective laser melted AlCu5MnCdVA. Mater Des 150:18-27. https://doi.org/10.1016/j.matdes.2018.04.003

14. Wang Z, Ummethala R, Singh N, Tang S, Suryanaraya C, Eckert J, Prashanth KG (2020) Selective laser melting of aluminum and its alloys. Materials 13:4564. https://doi.org/10.3390/ma13204564
15. Zhou X, An Z, Shen Z, Liu W, Yao C (2017) Particles control in selective laser melting in-situ oxide dispersion strengthened method. IOP Conf Ser Mater Sci Eng. https://doi.org/10.1088/ $1757-899 X / 167 / 1 / 012048$

16. Olsen J, Zhou X, Zhong Y, Liu L, Wang D, Yu C, Wang Y, Li K, Xing L, Ma J, Cui D, Liu W, Shen Z (2017) Tailoring hierarchical structures in selective laser melted materials. IOP Conf Ser Mater Sci Eng. https://doi.org/10.1088/1757-899X/219/1/012036

17. Wang L, Jue J, Xia M, Guo L, Yan B, Gu D (2016) Effect of the thermodynamic behavior of selective laser melting on the formation of in situ oxide dispersion-strengthened aluminum-based composites. Metals 6(11):286. https://doi.org/10.3390/met61 10286

18. Olakanmi EO (2013) Selective laser sintering/melting (SLS/ $\mathrm{SLM}$ ) of pure $\mathrm{Al}, \mathrm{Al}-\mathrm{Mg}$, and $\mathrm{Al}-\mathrm{Si}$ powders: effect of processing conditions and powder properties. J Mater Process Technol 213(8):1387-1405. https://doi.org/10.1016/j.jmatprotec.2013.03. 009

19. Louvis E, Fox P, Sutcliffe CJ (2011) Selective laser melting of aluminium components. J Mater Process Technol 211:275-284. https://doi.org/10.1016/j.jmatprotec.2010.09.019

20. Kimura T, Nakamoto $T$ (2017) Thermal and mechanical properties of commercial-purity aluminum fabricated using selective laser melting. Mater Trans 58(5):799-805. https://doi.org/10.2320/ matertrans.L-M2017809

21. Khairallah SA, Anderson AT, Rubenchik A, King WE (2016) Laser powder-bed fusion additive manufacturing: physics of complex melt flow and formation mechanisms of pores, spatter, and denudation zones. Acta Mater 108:36-45. https://doi.org/10. 1016/j.actamat.2016.02.014

Publisher's Note Springer Nature remains neutral with regard to jurisdictional claims in published maps and institutional affiliations. 